\title{
Korean Older Intimate Partner Violence Survivors in North America: Cultural Considerations and Practice Recommendations
}

Woochan Shim

Daejeon University, scholastica212@gmail.com

Holly Nelson-Becker

Loyola University Chicago, hnelsonbecker@luc.edu

Follow this and additional works at: https://ecommons.luc.edu/socialwork_facpubs

Part of the Social Work Commons

\section{Author Manuscript}

This is a pre-publication author manuscript of the final, published article.

\section{Recommended Citation}

Shim, Woochan and Nelson-Becker, Holly. Korean Older Intimate Partner Violence Survivors in North America: Cultural Considerations and Practice Recommendations. Journal of Women \& Aging, , : , 2009. Retrieved from Loyola eCommons, Social Work: School of Social Work Faculty Publications and Other Works, http://dx.doi.org/10.1080/08952840903054773

This Article is brought to you for free and open access by the Faculty Publications and Other Works by Department at Loyola eCommons. It has been accepted for inclusion in Social Work: School of Social Work Faculty Publications and Other Works by an authorized administrator of Loyola eCommons. For more information, please contact ecommons@luc.edu.

\section{cc) (†) $\ominus$}

This work is licensed under a Creative Commons Attribution-Noncommercial-No Derivative Works 3.0 License. (c) 2009 Routledge. 
Korean older intimate partner violence survivors in North America:

Cultural considerations and practice recommendations

\begin{abstract}
While literature on elder abuse has expanded, elder abuse by intimate partners has been less investigated. Even less is known about intimate partner violence among older Koreans living in North America. This article identifies important cultural considerations for individuals helping the Korean older adult community beginning with the definition of intimate partner violence in this community and barriers to leaving that include traditional views of the East Asian self. Current practice interventions are discussed and recommendations for future practice such as healing han, the accumulated suffering from years of abuse, are suggested. The ultimate goal of this paper is to expand awareness in order to develop the best culturally competent prevention and intervention practice for Korean older intimate partner violence survivors in North America.

Key words: elder abuse, domestic violence, intimate partner violence, older battered women, Korean immigrants
\end{abstract}

Introduction

Elder abuse by intimate partners has not been thoroughly investigated in the literature. There is even less reported about this concern in the immigrant Korean population. Yet, as in many communities, anecdotal information indicates this issue causes distress and dysfunction in some emigrant Korean families. In order to understand the phenomena of older intimate partner violence (IPV) among Korean immigrants, it is important to first consult existing literature on elder abuse and domestic violence in nonminority communities as well as other East Asian minority communities in particular. Secondly, after such analysis, it is possible to particularize and translate those insights into the context of the Korean community in North America. There are similarities but also differences in the experiences of IPV among older Korean 
survivors compared to other racial groups. This article reviews literature on elder abuse and domestic violence that can have particular significance and relevance for the Korean community. Current practice interventions are identified and recommendations for future practice and research are suggested. The ultimate goal of this paper is to expand awareness in order to develop the best culturally competent prevention and intervention practice for older Korean IPV survivors in North America.

\section{Culturally Competent Definitions of Older Adult Intimate Partner Violence}

The fields of IPV and gerontology use language that does not fully capture the needs of minority clients within their fields. In IPV, older women survivors are perceived as being a minority. Therefore, the target of prevention and intervention programs is usually younger women. In gerontology, the issue of abuse within intimate relationships is seldom recognized as a problem because it is not a focus of assessment. When the term "battered women" is used, older women are often not included; when the term "abused older adults" is heard, seldom is the possibility of an intimate partner as perpetrator considered. Vinton (1991) suggests not using "battered women" or "abused elders" in describing older intimate partner abuse survivors, for each excludes the other. Thus, there is a need for defining elder IPV that addresses the invisible population that has been excluded from the elder abuse and the IPV fields: older adult intimate partner violence victims.

Intimate partner violence includes threat or use of any type of violence (physical, sexual, verbal, emotional, financial, and spiritual) perpetrated primarily against women by their current or former spouse, girlfriend or boyfriend (see Yllo \& Bograd, 1988; and Walker, 1994). Intimate partners who practice this do so in order to gain and maintain power and control over the victim. Since this concept views the problem to be the power imbalance between the victim and the perpetrator condoned by society, generally accepted interventions do not stop at addressing the power imbalance within a couple's relationship. Interventions now include supportive approaches at the individual level and law enforcement responses at the societal level to empower the victim and punish the perpetrators. 
Elder abuse is defined as "any knowing, intentional, or negligent act by a caregiver (emphasis added) or any other person that causes harm or a serious risk of harm to an older adult" (National Center on Elder Abuse, September 2005, p. 2). Elder abuse protection laws tend to view the victim as the one who needs to be cared for and the perpetrator as the caregiver (Bergeron, 2001), regardless of the dysfunctional gender or couple dynamics in place previous to one spouse becoming physically frail. Thus, elder abuse emphasizes the possibility of the caregiver as the perpetrator while neglecting the possibility of an intimate partner (who may not be a caregiver) as the perpetrator.

The above definitions of elder abuse and intimate partner violence (IPV) have been formulated by European American investigators and thus estimating the prevalence of IPV in minority communities is difficult because of differing cultural interpretations. This is particularly true for East Asian women in North America because of cultural understandings: some women regard abusive behavior as merely a reflection of challenging personality traits. This is the case with Chinese and Korean domestic violence survivors. Chinese Americans tend to label their batterers as "men with hot-temper" or "frustrated men with stress"; anything but "battering men" (Lee \& Au, 1998). Likewise, Korean American women often do not identify their husbands' abusive behavior as violence. Instead, Korean survivors of IPV show a tendency to label their batterers' abusive and controlling behaviors as "being morbidly suspicious of their wives." (First author's personal anecdotal experiences working with Korean survivors in New York from 1996 to 1998.) In addition, unless the violence involves physical abuse that leaves cuts and bruises, Korean survivors would describe their experience as couple conflicts, disputes, or personality clashes; anything other than intimate partner violence. The older Korean population may show more of this "it's not intimate partner violence" tendency because the concept of IPV was only recently introduced and publicized in Korean society by the passage of the Domestic Violence Prevention Act in December 1997. This calls for further research on exploring the types or forms of IPV seen, heard, and experienced by Korean older adults without using the term IPV in the research. 


\section{Culturally Competent Interventions for Elder Intimate Partner Violence}

Some researchers argue that older IPV survivors have special needs to which practitioners should pay attention. Although it is generally considered unusual for women over sixty who are victims of violence to seek services through domestic violence programs, two studies substantiated that at least some older adults who are victims of violence do so with unique needs. Lundy and Grossman (2004) examined the experiences of 1,057 victims of domestic violence age sixty-five and older who sought refuge, support, and services from domestic violence programs between 1990 and 1995. Older women add the problem of domestic violence to all the other adjustments of this later life span, which may include health concerns, decreasing friendship and familial network sizes, and financial instability. This constellation of factors may make older women more difficult to serve in domestic violence programs. Wilke and Vinton's (2005) study examined the nature and extent of IPV and its impact on psychosocial functioning among women of different age groups. Findings confirmed that older women experience just as much IPV as younger women, but had more needs than younger women.

Literature has given scant attention to special concerns of Korean minority older IPV survivors. Lacking is any information to clearly guide practice. There are only a few IPV-related empirical studies with practice implications about Korean Americans (Shim \& Hwang, 2005; Kim \& Sung, 2000; Lee, 2007; Song, 1989). Culturally appropriate suggestions for treatment from these studies could be applied to older women. However, these studies do not address older women specifically. Thus, there is a clear need to incorporate knowledge we have gained from studies on IPV and elder abuse in the general population with what we know about East Asian culture, Korean to be specific, to identify practice implications for Korean survivors of IPV.

Barriers to Help-seeking or Leaving in Violent Intimate Partner Relationships The common challenge in preventing and intervening in IPV cases arises from the fact that survivors in general are reluctant to report their IPV experiences and ask for help in preventing further 
violence. For older Koreans, there may be more barriers to help seeking or leaving the IPV experience compared to non-minority survivors. Individual cases of IPV are underreported because perpetrators and victims tend to deny or minimize the seriousness of the violence. Several reasons why older intimate partner violence (IPV) survivors find reporting or help-seeking more difficult than younger generations have been identified (Straka \& Montiminy, 2006; Beaulaurier, Seff, Newman, \& Dunlop, 2005). First, older women are more likely to have been socialized with more traditional attitudes and values. Thus they might believe that domestic violence should be kept a secret, women need to be loyal to their husband, divorce is unacceptable, or they are the cause of the abuse. Second, older women are more likely to feel hopeless and financially dependent on the abusive partner than the younger population. They are less likely to have worked in the past and to be eligible to find employment in the future. Third, older women are more likely to be helpless and physically dependent on their abusive partner because of health or functional problems. Fourth, older women may have been in an abusive situation for so long that they may not realize that there are choices. They may see no other alternatives. This last reason is particularly disempowering and devastating as it limits the ability of abused older women to live life in a conscious vital way. Studies on older Asian Americans' help-seeking behaviors caution that older Korean Americans are less aware of and less likely to seek help from formal helping systems compared to other racial groups (Moon \& EvansCampbell, 1999). This may be due to a unique aspect to the help-seeking barrier, namely the patriarchal culture.

Influence of a Male-dominant Culture on Korean Older Adults

The organizational structure of the family may have an influence in older IPV phenomena within East Asian families. The legal status of older women places them in a more vulnerable situation than their spouses, since wives are often sponsored by their husbands for permanent residency or citizenship (Patterson \& Malley-Morrison, 2006; Raj \& Silverman, 2002). This is particularly true in the family structure of East Asian older adults who are influenced by patriarchal culture. An example of a patriarchal cultural 
norm that influences Korean women even today is the rule of the three obediences of a woman of the Joseon dynasty (1392-1910 A.C.). This is called "Sam Jong Ji Do"-[Korean Romanization] and it means that a woman must be obedient to the father before marriage, to the husband after marriage, and to the son after the husband's death. Thus when an older woman needs a legal guardian, it is most likely the husband who will take that role and then the oldest son after the husband dies.

Rooted in Confucianism, the traditional East Asian self exists primarily in relationships to significant others and in communal context (Chu, 1985; Ho, 1990; Lee, 2006). Thus, when individual well-being clashes with that of a family, it is expected that an individual will subjugate her or his well-being for the collective good. Family problems are viewed as shameful and something to be hidden, previously found to be an internal barrier to help-seeking behavior among English and Spanish speaking populations as well (Beaulaurier, Seff, Newman, \& Dunlop, 2005).

Due to the combination of influences from a patriarchal culture and Confucianism, Korean women may find it virtuous to put themselves down by saying that they are inferior, shameful, and meaningless (Lee, 2006), compared to men in general and to husbands in particular. Unlike the individualism valued in western culture, communal personhood is valued in Korean society. Communal personhood means "the value of the individual ... depends on how well a person adopts communal norms and functions to promote social harmony" (Lee, 2006, p. 344). Thus, Korean older women who were socialized traditionally are more likely to have self-silenced during a fight and submitted to the husband's controlling behavior. In addition, Korean women are less likely to seek outside help when experiencing IPV. If abused women seek formal services, the Korean community may consider these women to taint the reputation of the family and the community as a whole (Shim \& Hwang, 2005). When older immigrants have difficulties adapting to Western culture and language, they would not know how or where to report their situation nor how to recognize themselves as victims of domestic abuse (Manigbas, 2002). Any of the above reasons, in other words, lack of acculturation, may hinder an older East Asian woman from seeking help and/or leaving an abusive 
partner.

\section{Limited Language Fluency}

Some argue that reticence to seek help coexists with limited English language proficiency of the older adult. For example, while older Koreans who were interviewed in Korean were less likely than Caucasians to seek help regarding elder abuse (Moon \& Williams, 1993), older Koreans who were interviewed in English were found to be similar to Caucasians (Pablo \& Broun, 1997). In other words, Koreans who spoke English were no more or less reluctant than Caucasians to report their victimization. Culturally and linguistically sensitive practice suggests that language barriers are important to address in order to improve effective responses in older Korean women

\section{Recommendations for Practice}

Older Korean women face difficulty in responding to the situation and leaving abusive partners due to traditional gender roles and cultural proscriptions mentioned above. It is important to consider what can be done to help; therefore, we make some intervention suggestions.

\section{Assessment}

As detailed earlier, older IPV survivors may not easily disclose their experiences. In addition, older couples' IPV is less likely to be physical (Straka \& Montminy, 2006), and for that reason, less visible. This calls for helping professionals who are likely to encounter older Koreans to be alert for long term effects of previous IPV as well as non-physical IPV for appropriate assessment and intervention. Especially, physicians, social workers, and other health professionals should consider that age-related stressors, such as poor physical health and a high level of depression and anxiety, may be related to early and repeated trauma to which older women have been exposed. Thus comprehensive assessment that includes earlier trauma history is crucial (Franco, 2007).

When older survivors do reach professional helping systems such as the formal health care system, the assessment process can raise awareness that physical and mental abuse is not normative treatment 
within a marital relationship. This heightened awareness can help these older women to see detrimental effects of IPV on their physical and mental health. Also, it can help them to begin to envision how an ideal relationship without violent interactions might look. With support of professional helpers and/or informal support networks, older IPV survivors can learn new behavioral skills that can lessen risks for violence and increase their satisfaction. An example will be detailed more fully in the Discussion section.

Shelter

Earlier studies on shelter sensitivity to elder abuse issues reported that older survivors of domestic violence tended not to use shelter services and thus with little need, specific programs for older women were never developed (Smith, 1999). However, more recent studies show an encouraging trend that an increasing number of shelters do offer programs for older domestic violence survivors (Vinton, 1998, 1999). Those who received services from a shelter benefited and were able to move ahead in their lives (Hightower, Smith, Ward-Hall, \& Hightower, 1999). More interagency collaboration would also strengthen assistance for women of color (Fisher et. al., 2003).

However, it is questionable if current shelter services are culturally appropriate for older Korean survivors. In Korean culture, when a wife leaves home even temporarily, it is often considered to express her desire to permanently sever the relationship with her partner. This belief comes from Confucian philosophy that separates the place of men and women: women to control inside domains and men to control outside spheres. According to the Five Relationships rule, there must be love between father and son, duty between ruler and subject, distinction between husband and wife, precedence of the old over the young, and trust between friends (Mencius 3A:4; cited in Tu, 1998). This serves as a functional distinction of male and female roles. Male role activity emphasizes the public economic and political domain while female role activity emphasizes the private family and household domain. Thus shelter utilization to remove oneself from further violence may be perceived as contravening basic Confucian philosophy. Furthermore, since divorce is viewed as a failure in fulfilling a wife's duty to keep the family together, a divorced woman 
would lose family support and resources from the community which would make it far more difficult for an immigrant woman to survive. Thus, for Korean immigrant women, especially if they have a language barrier, a mainstream shelter service would be least likely to meet their needs.

Young or old, Korean survivors would feel isolated and challenged even with such everyday choices as the food they are served or the food they are asked to help prepare for other residents. Programs developed and run by predominantly English speakers also could fail to meet cultural needs of this population. Thus, for Korean immigrants, shelters may not be a culturally prudent arrangement unless they are condoned, supported, and/or run by the Korean community. Shelters within the Korean immigrant community would assist in sending out a message to survivors that leaving the perpetrator by staying at a shelter does not necessarily mean having to sever the relationship with the community or cultural roots.

However, shelters run by the Koreans will not fully deal with the fear of institutionalization among older women. Unlike younger survivors, older survivors have one more significant fear: fear of institutionalization (National Center on Elder Abuse, September, 2005). If the partner is a caregiver, then the possibility of institutionalization becomes higher if the abused partner chooses to leave. In this situation, the older woman may need placement in an assisted living facility or nursing care facility to meet physical health needs. Therefore, in order to deal with the fear of institutionalization, community education and support is highly recommended.

Support Groups for Non-shelter Users

A non-residential support group intervention is particularly imperative for those who choose not to use a residential service (either IPV shelter or nursing home) and for those who survived severe IPV when young yet remained in the relationship. Korean older survivors are likely to fall into this category considering their socialization influenced by Confucianism as described earlier. Zink and her colleagues (2006) interviewed 38 women older than age 55 years. Their grounded theory analysis demonstrated that women who remained in their abusive relationships employed mainly cognitive (emotion-focused) 
strategies to find meaning in a situation that was perceived as unchangeable. By reappraising themselves, their spouses, and their relationships they refocused energies in certain roles, set limits with their abusers, and reached out to others (friends, family, and community organizations). Some women appeared to thrive, others merely survived, but all maintained the appearance of conjugal unity. Sometimes this appearance alone facilitates ongoing community acceptance and thus important social support. The remaining question is how can we help them thrive? Building spiritual supports is one important way to enhance individual and communal strengths for IPV survivors.

\section{Spirituality}

As discussed earlier, interventions for IPV have mainly provided empowerment services including shelter, group counseling services, and changes to the criminal justice system to hold perpetrators accountable. Lately, there is growing interest in issues related to spirituality and religion among feminists and others in the social service community. This results in more holistic social work approaches (NelsonBecker, 2005; Nelson-Becker, Nakashima, \& Canda, 2006).

Older women with traditional attitudes and values who are also religious are at greater risk to remain silently in an abusive situation (Zink, Regan, Jacobson, \& Pabst, 2003). Older adult maltreatment is often invisible and can only be detected by someone who has developed a trusting relationship through prolonged engagement with the victim. Qualitative studies of religious leaders' knowledge, perceptions, and responses to elder abuse in Toronto and Ontario, emphasized that religious leaders play an integral role in elder abuse survivors' lives and could have a very strong impact on preventing, detecting, and resolving elder abuse (Podnieks \& Wilson, 2003a, 2003b). These studies found that religious leaders were well aware of elder abuse, although they downplayed it in their own community. However, the studies failed to demonstrate that religious leaders were particularly aware of or sensitive to older IPV issues.

Regardless of the fact that majority of Korean immigrants rely on their church for social and even financial support, there has been little investigation concerning how religion and/or spirituality may affect 
Korean immigrant IPV survivors. Studies of older Korean immigrants reveal that religious coping skills such as practicing forgiveness contributed to improving self-reported life satisfaction and self-efficacy (Lee, 2007). On the other hand, there is also an argument that the patriarchal God image can negatively affect Korean Christian women when it is combined with the deep-seated patriarchal Confucianism in Korean culture (Kim, 2006).

Scholars of Korean religion have discussed the concept of Korean women's experience of han, but lacking is a discussion on ways to heal han. The concept of han is related to the experience of IPV as han is described as "a black hole, when suffering reaches the point of saturation, it implodes and collapses into a condensed feeling of pain. This collapsed feeling of sadness, despair, and bitterness is han" (Park, 1989, pp. 50-51). "Han, as an accumulated feeling of sorrow, pain, and deep bitterness that comes from being unjustly treated and abused for a long period of time...[is] caused by the combinations of historical, political, economical, social, and cultural oppressions that are unique to Korean women" (Kim, 2007, p. 725). Kim (2007) argues that Korean immigrant women's experience of political, economic, social, and cultural oppression is even more severe since they are caught between two cultures: Korean and American. This concept is similar to the feelings of helplessness and hopelessness known to result from IPV. The concept of han has not yet been applied to explain the feelings of IPV survivors, yet it suggests remarkable capacity to describe the experience of IPV.

The limited literature regarding han healing describes key concepts that resemble feminist therapy process. For example, Wood and Middleman (1992) describe three sequential tasks that include: 1) provision of mutual support by having survivors share their stories in a group setting; 2) development of consciousness-raising by realizing that other women experience gender-based violence in our patriarchal society; and 3) creation of an action plan to prevent and stop violence against women. Likewise, Park (1989) describes 1) awakening as a process of identifying aspects of one's personal situation that creates and causes han as well as the historical, political, economical and societal condition that oppresses and 
creates collective han, and 2) disentanglement, which includes confronting han-causing problems with a vision of how to transform the situation, and the transcendent experience of han-puri. Han-puri is a unique healing practice involving Korean traditional shamans replaying the process of the tragic event or oppressive victimization that caused han (Kwon, 2004; Park, 1989). By retelling the full story of whatever event resulted in han, the sorrowful person begins to identify their feeling of han and can vision ways to prevent future painful events by utilizing the han-energy positively. Identifying one's own limitations while also recognizing one's remarkable possibilities can become a transcendent experience.

\section{Discussion}

What we have learned in searching the literature for this paper and shown through our review is that there has been a lack of attention to the important needs of older Korean women who suffer from IPV. This problem has been under-identified in a community where seeking help outside a marriage bond is often culturally restricted because of traditional beliefs. Definitions commonly used in the domestic violence field have only heightened this concern by overlooking the problem of IPV in older women; even professionals working in this field are generally not aware of the special difficulties encountered by East Asian women, here detailed particularly in examples with a Korean immigrant population.

Compartmentalization among the fields of elder abuse, IPV, and minority communities have led to barriers in knowledge dissemination that, if fully accessible, would heighten both identification and treatment for these women whose problems lie hidden in the social isolation of a minority language and the traditional patriarchal teachings of how they ought to act in relationships, no matter the emotional or physical cost. Because of this failure to consider the unique aspects of traditional Korean marital dynamics, older Korean women who are IPV victims have little opportunity to imagine how their primary relationships could change.

What are some of the culturally competent strategies that could help professionals to prevent and intervene in IPV among Korean older immigrants in North America? From our review of the literature and our own practice wisdom, we make both macro level and micro level recommendations. Our macro level 
recommendations involve 1) raising awareness of community service providers that minority women are likely to access, such as health care providers; 2) intentional education programs to raise awareness and prevent IPV; and 3) structural changes in the way mainstream shelters are organized so that they can accommodate needs of Korean and other minority older women. Our micro level recommendations involve 1) employing han-puri and other culture-specific anthropological tools; 2) looking for a sense of coherence or meaning, and 3) in situations where safety is not at risk, changing interpersonal patterns of interaction.

\section{Macro Level Interventions}

First of all, mainstream health care professionals must actively assess current and past IPV when Korean older adults receive medical care. This is especially important since Korean immigrant elders are reluctant to seek help specifically for their IPV situation. Further, when medical professionals conduct the assessment, they should carefully select a Korean interpreter who will help interpret language subtleties and cues that might otherwise be missed. Before bringing in an interpreter, especially from a small immigrant community where most members know each other, professionals must consult with the client/patient to determine whether they would feel comfortable talking with an interpreter present. At times, they might prefer using a language help-line where an interpreter cannot see the face of the client/patient, thus ensuring confidentiality. Also of vital importance is to understand that age-related illnesses such as depression, anxiety, and physical frailty may also be related to an IPV history.

Secondly, aggressive public education and outreach in Korean immigrant communities has the potential to raise awareness of IPV and make it unacceptable in the community. Korean religious leaders and secular Korean immigrant leaders need to be aware of the signs and detrimental long-term effects of IPV even when it occurred years ago. Public education regarding ways to build and maintain healthy marriages may stimulate behavior change among Korean immigrants. Together with helping the public identify violent or unhealthy marital behavior, knowledge and skills to maintain healthy intimate relationships must be included in public education. When people do choose to marry, the community has 
an interest in helping maintain solid marriage relationships, with a wide continuum of how that is defined and how the marriage may adapt and expand to fulfill different needs and desires of the couple.

Related to the above issue is the third suggestion regarding services obtained through IPV shelters. Mainstream shelters are not age and culture sensitive, so we must carefully assess whether shelter services are appropriate for older Korean immigrants. Especially since women's place is understood to be in the domestic sphere, the metaphoric meaning of leaving home and staying elsewhere may imply ending the marriage among conservative Korean immigrants. In addition, due to fear of institutionalization among older adults cross culturally, we should consider alternative ways to reach out to older IPV survivors. Suggestions include: a) shelter services offered by the Korean immigrant community to send out a message that the community condones the idea of women leaving home to stay safe; and b) nonresidential group supports for those who wish to remain in the relationship that facilitate empowerment by others in similar situations. Lastly, the authors suggest use of religious and spiritual strategies in healing survivors of IPV.

Micro Level Interventions

The first micro level intervention concerns the concept of the transcendent experience of han-puri that was introduced in the prior section of the paper as utilizing traditional Korean spirituality in healing IPV survivors. Survivors may hold grudges or han when realizing that they have lived through IPV all these years and sacrificed to hold the family together. Han may be expressed as a sense of "lost time" or emptiness in life. However, through a consciousness-raising process of self-realization and group acknowledgement that IPV is experienced by many women as gender-based oppression, survivors may be able to reappraise themselves as heroines and survivors. By retelling and revisiting the life-long experience of IPV with other women, a group of survivors may start to feel proud of the strengths they developed in surviving. This may lead them to plan for group action of transforming society to be more egalitarian, or simply give them the freedom to grow in ways previously unimagined. 
Secondly, the way a victim processes violence is critical in anticipating whether or not trauma and detrimental effect will be experienced. The concept of sense of coherence (SOC) has great potential in understanding why certain IPV victims survive well and in helping other victims survive better after the victimization. SOC is the ability to perceive a stressor as comprehensible, manageable, and meaningful. SOC seemed to buffer the impact of a recent stressful life event on self reported health status among a nationally representative sample of 6505 Canadians aged 30 years of age or greater (Richardson \& Ratner, 2005). Other large studies suggest that a sense of coherence was positively related to physical, social, and mental health as well as living conditions and social support (Holmberg, Thelin, \& Stiernstrom, 2005; Read, Aunola, Feldt, Leinonen, \& Ruoppila, 2005). While SOC has not been explored with spiritual or religious variables and particularly with IPV, it holds promise as lens that may help individuals to see that their lives are larger than the events that happen to them.

The last recommendation may look somewhat controversial as it involves redefining a relationship. One does that by first changing one's own behavior in a stance similar to Gandhi's approach in India. It may be possible to educate the minority older abused woman about ways to change her behavior to maintain her dignity and yet not engage with violence. A nonviolent response may disarm her partner and provide new kinds of solutions. A partner who refuses to engage with violent means by offering humor or other unexpected response can actively take control without appearing to dominate. To transform behavior one must first notice it, and secondly be willing to break entrenched habits that hurt rather than help. An important goal is to restore communication in healing ways. When one person seeks to make another suffer, she/he thinks that her/his own suffering will be relieved, but this punishment leads to greater suffering for both (Hanh, 2001). When people can mindfully recognize and reflect on their negative emotions, they can develop the tools to transform these unwanted feelings. Unlike younger IPV victims, older women often choose to stay with their partners. Thus ways must be found to help these women regain their own center; to learn not to internalize verbal abuse; not to blame themselves; not to take 
responsibility for the abuser's behavior; and finally to release suffering through learning to forgive the batterer and herself. In these ways, IPV survivors can be empowered from within and also create their own base of empowerment for the marriage.

\section{Conclusion}

In this article, we have called attention to concerns about IPV among older couples and made culturally sensitive practice suggestions to better address older Korean immigrants' needs based on our review of the literature and our own practice wisdom. We urge professionals in domestic violence and elder abuse fields, as well as medical professionals, to assess current and past experiences of IPV when older clients seek help. To accomplish the goal of providing culturally sensitive services to older Korean immigrants, we offered both macro and micro practice suggestions. We acknowledge the limitations of our suggestions as they are not based on research, but rather on practice experience. As a next step, research should explore Korean older couples' relationship needs and strategies to maintain these relationships free of violence. Future research should also explore the applicability of traditional Korean spirituality (e.g., the concept of han-puri, Shamanism, Confucianism, and Buddhism) with older Korean immigrants who have been influenced by American culture, especially Christianity. We believe that acknowledging the unique cultural and social context of older Korean immigrants is the first step towards preventing and ending the cycle of IPV among Korean immigrants.

\section{References}

Beaulaurier, R. L., Seff, L. R., Newman, F. L., \& Dunlop, B. (2005). Internal barriers to help seeking for middle-aged and older women who experience intimate partner violence. Journal of Elder Abuse \& Neglect, 17(3), 53-74. doi:10.1300/J084v17n03 04

Bergeron, L. R. (2001). An Elder Abuse Case Study: Caregiver Stress or Domestic Violence? You Decide. Journal of Gerontological Social Work, 34(4), 47-63. doi:10.1300/J083v34n04_05 
Chu, G. (1985). The changing concept of self in contemporary China. In A. J. Marsella, G. DeVos, \& F. L. K. Hsu (Eds.), Culture and self, Asian and Western perspectives. New York: Tavistock Publications.

Fisher, B. S., Zink, T., Pabst, S., Regan, S., \& Rinto, B. (2003). Services and Programming for Older Abused Women: The Ohio Experience. Journal of Elder Abuse and Neglect, 15(2), 67-83. doi:10.1300/J084v15n02_04

Franco, M. (2007). Posttraumatic Stress Disorder and Older Women. Journal of Women \& Aging, 19(1/2), 103-117. doi:10.1300/J074v19n01_07

Hanh, T. N. (2001). Anger: Wisdom for cooling the flames. New York: Riverhead Books.

Hightower, J., Smith, M. J., Ward-Hall, C. A., \& Hightower, H. C. (1999). Meeting the Needs of Abused Older Women? A British Columbia and Yukon Transition House Survey. Journal of Elder Abuse and Neglect, 11(4), 39-57. doi:10.1300/J084v11n04_04

Ho, C. K. (1990). An analysis of domestic violence in Asian American communities: A multicultural approach to counseling. Women \& Therapy, 9(1//2), 129-150. doi:10.1300/J015v09n01_08

Holmberg, S., Thelin, A., \& Stiernstrom, E. (2004). Relationship of Sense of Coherence to other psychosocial indices. European Journal of Psychological Assessment, 20(4), 227-236. doi:10.1027/1015-5759.20.4.227

Kim, J. Y., \& Sung, K. (2000). Conjugal violence in Korean American families: A residue of the cultural tradition. Journal of Family Violence, 15(4), 331-345.

Kim, S. S. (2006). A Korean feminist perspective on God representation. Pastoral Psychology, 55, 35-45. doi:10.1007/s11089-006-0030-5

Kim, S. S. (2007). Psychological contours of multicultural feminist hermeneutics: Han and relationality. Pastoral Psychology, 55, 723-730. doi:10.1007/s11089-007-0089-7

Kwon, S. Y. (2004). How do Korean rituals heal? Healing of han as cognitive property. Journal of Pastoral Theology, 14(1), 31-45. 
Lee, B. (2006). Caring-self and women's self-esteem: A feminist's reflection on pastoral care and religious education of Korean-American women. Pastoral Psychology, 54(4), 337-353. doi:10.1007/s11089$\underline{005-0004-z}$

Lee, M., \& Au, P. (1998). Chinese battered women in North America: Their experiences and treatment. In A. R. Roberts (Ed.), Battered women and their families: Intervention strategies and treatment programs (2nd ed., pp. 448-482). NY: Springer.

Lee, E. O. (2007). Religion and spirituality as predictors of well-being among Chinese American and Korean American older adults. Journal of Religion, Spirituality, \& Aging, 19(3), 77-100. doi:10.1300/J496v19n03_06

Lundy, M., \& Grossman, S. F. (2004). Elder Abuse: Spouse/Intimate Partner Abuse and Family Violence among Elders. Journal of Elder Abuse and Neglect, 16(1), 85-102.

Manigbas, M. (2002). Multiservice Organization combats elders abuse in Chinese community. Generations, $26(3), 70-71$.

Moon, A., \& Evans-Campbell, T. (1999). Awareness of formal and informal sources of help for victims of elder abuse among Korean American and Caucasian elders in Los Angeles. Journal of Elder Abuse \& Neglect, 11(3), 1-23. doi:10.1300/J084v11n03_01

Moon, A., \& Williams, O. (1993). Perceptions of elder abuse and help-seeking patterns among AfricanAmerican, Caucasian American and Korean-American elderly women. The Gerontologist, 33(3), 386-395.

National Center on Elder Abuse (September 2005). Domestic violence: Older women can be victims too. Retrieved November 18, 2007 from http://www.ncea.aoa.gov/NCEAroot/Main_Site/pdf/publication/OLDERWOMEN2COLUMNFINAL10-11-05.pdf. 
Nelson-Becker, H. (2005). Religion and coping in older adults. Journal of Gerontological Social Work, $45(1 / 2), 51-68$.

Nelson-Becker, H., Nakashima, M. \& Canda, E. R. (2006). Spirituality in professional helping interventions. In B. Berkman \& S. D'Ambruoso (Eds.), Oxford handbook of social work, health, and aging (pp.797-07). Boston: Oxford Press.

Pablo, S., \& Braun, K. L. (1997). Perceptions of elder abuse and neglect and help-seeking patterns among Filipino and Korean elderly women in Honolulu. Journal of Elder Abuse \& Neglect, 9(2), 63-76.

Park, A. S. (1989). Theology of han (the abyss of pain). Quarterly review-United Methodist Board of Higher Education and Ministry, 9(1), 48-61.

Patterson, M., \& Malley-Morrison, K. (2006). A cognitive-ecological approach to elder abuse in five cultures: Human rights and education. Educational Gerontology, 32, 73-82. doi:10.1080/03601270500338666

Podnieks, E., \& Wilson, S. (2003a). Elder abuse awareness in faith communities: Findings from a Canadian pilot study. Journal of Elder Abuse and Neglect, 15(3/4), 121-135. doi:10.1300/J084v15n03_08

Podnieks, E., \& Wilson, S. (2003b). An exploratory study of responses to elder abuse in faith communities. Journal of Elder Abuse and Neglect, 15(3/4), 137-162. doi:10.1300/J084v15n03_09

Raj, A., \& Silverman, J. (2002). Violence against immigrant women: The roles of culture, context, and legal immigrant status on intimate partner violence. Violence Against Women, 8(3), 367-398. doi:10.1177/10778010222183107

Read, S., Aunola, K., Feldt, T., Leinonen, R., \& Ruoppila, I. (2005). The relationship between generalized resistance resources, sense of coherence, and health among Finnish people aged 65-69. European Psychologist, 10(3), 244-253. doi:10.1027/1016-9040.10.3.244 
Richardson, C. G., \& Ratner, P. A. (2005). Sense of coherence as a moderator of the effects of stressful life events on health. Journal of Epidemiology \& Community Health, 59(11), 979-984. doi:10.1136/jech.2005.036756

Shim, W., \& Hwang, M.J. (2005). Implications of an arrest in domestic violence cases: Learning from Korean social workers' experiences in the U.S. Journal of Family Violence, 20(5), 313-328. doi:10.1007/s10896-005-6607-4

Smith, G. (1999). Transition houses: Do they meet the needs of older women? BC Institute Against Family Violence Newsletter, 6(1). Retrieved February 21, 2003, from http://www.bcifv.org/resources/newsletter/1999/winter/transition_house.shtml

Song, Y. I. (1989). The silent suffering of abused Korean immigrant women. Korea Observer, 20(3), 303320.

Straka, Silvia M., \& Montminy, Lyse. (2006). Responding to the needs of older women experiencing domestic violence. Violence Against Women, 12(3), 251-267. doi:10.1177/1077801206286221

Tu, W. (1998). Probing the 'Three Bonds' and 'Five Relationships,' In Walter H. Slote \& George A. De Vos, (Eds.), Confucianism and the Family (pp. 121-136), Albany: State University of New York Press.

Vinton, L. (1991). Abused Older Women: Battered Women or Abused Elders? Journal of Women \& Aging, 3(3), 5-19.

Vinton, L. (1998). A Nationwide Survey of Domestic Violence Shelters' Programming for Older Women. Violence Against Women, 4(5), 559-571.

Vinton, L. (1999). Working with Abused Older Women from a Feminist Perspective. Journal of Women \& Aging, 11(2-3), 85-100. doi:10.1300/J074v11n02_07

Walker, L. E. A. (1994). Abused Women and Survivor Therapy: A Practical Guide for the Psychotherapist. Washington, DC: American Psychological Association. 
Wilke, D. J., \& Vinton, L. (2005). The Nature and Impact of Domestic Violence across Age Cohorts. Affilia, 20(3), 316-328. doi:10.1177/0886109905277751

Wood, G. G., \& Middleman, R. R. (1992). Groups to empower battered women. Affilia, 7, 82-95. doi:10.1177/088610999200700406

Yllo, K., \& Bograd, M. (1988). Feminist Perspectives on Wife Abuse. Thousand Oaks, CA: Sage.

Zink, T., Regan, S., Jacobson, C. J. Jr., \& Pabst, S. (2003). Cohort, Period, and Aging Effects: A Qualitative Study of Older Women's Reasons for Remaining in Abusive Relationships. Violence Against Women, 9(12), 1429-1441. doi:10.1177/1077801203259231

Zink, T., Jacobson, C. J., Jr., Pabst, S., Regan, S., \& Fisher, B. S. (2006). A Lifetime of Intimate Partner Violence: Coping Strategies of Older Women. Journal of Interpersonal Violence, 21(5), 634-351. doi:10.1177/0886260506286878 